Please do not remove this page

RMIT

UNIVERSITY

\title{
Design and implementation of finite state machine decoders for phase disposition pulse width modulation of modular multilevel converters
}

Teixeira, Carlos; Sun, Yichao; Holmes, Grahame; McGrath, Brendan

https://researchrepository.rmit.edu.au/esploro/outputs/9921860312701341/filesAndLinks?institution=61RMIT_INST\&index=null

Teixeira, C., Sun, Y., Holmes, G., \& McGrath, B. (2016). Design and implementation of finite state machine decoders for phase disposition pulse width modulation of modular multilevel converters. Proceedings of the IEEE Energy Conversion Congress and Exposition (ECCE 2016), 1-8.

https://doi.org/10.1109/ECCE.2016.7855008

Document Version: Accepted Manuscript

Published Version: https://doi.org/10.1109/ECCE.2016.7855008

Repository homepage: https://researchrepository.rmit.edu.au

(C) 2016 IEEE

Downloaded On 2023/04/26 21:17:35 +1000 
Thank you for downloading this document from the RMIT Research Repository.

The RMIT Research Repository is an open access database showcasing the research outputs of RMIT University researchers.

RMIT Research Repository: http://researchbank.rmit.edu.au/

\section{Citation:}

Teixeira, C, Sun, Y, Holmes, G and McGrath, B 2016, 'Design and implementation of finite state machine decoders for phase disposition pulse width modulation of modular multilevel converters', in Proceedings of the IEEE Energy Conversion Congress and Exposition (ECCE 2016), Milwaukee, United States, 18-22 September 2016, pp. 1-8.

See this record in the RMIT Research Repository at:

http://researchbank.rmit.edu.au/view/rmit:40110

Version: Accepted Manuscript

Copyright Statement:

(C) () 2016 IEEE

\section{Link to Published Version:}

http://dx.doi.org/10.1109/ECCE.2016.7855008 


\title{
Design and Implementation of Finite State Machine Decoders for Phase Disposition Pulse Width Modulation of Modular Multilevel Converters
}

\author{
C. A. Teixeira ${ }^{1}$ \\ Y. Sun ${ }^{2}$ \\ D. G. Holmes ${ }^{1}$ \\ B. P. McGrath ${ }^{1}$ \\ ${ }^{1}$ School of Engineering, RMIT University, Melbourne, Australia \\ ${ }^{2}$ School of Electrical Engineering, Southeast University, Nanjing, China \\ carlos.teixeira@rmit.edu.au \\ yichao.sun1987@gmail.com \\ grahame.holmes@rmit.edu.au \\ brendan.mcgrath@rmit.edu.au
}

\begin{abstract}
It is well known that level shifted phase disposition pulse width modulation (PD-PWM) achieves the best possible three-phase line-to-line output voltage spectrum for multilevel converters. However the strategy does require post modulation signal decoding to optimally select between redundant switched states and to achieve an even distribution of commutation events across all switching devices. For modular multilevel converters (MMCs), PD-PWM involves firstly scheduling the individual module switching events of both arms as an integrated process to achieve optimal harmonic performance, and then selecting between redundant states to balance the individual module capacitor voltages, and to also minimise the phase leg high frequency circulating currents. This paper discusses the design and implementation of finite state machine PD-PWM post modulator decoders for MMCs to achieve these objectives. The proposed approach has been verified in simulation and then with experimental confirmation using a two module per arm MMC.
\end{abstract}

\section{INTRODUCTION}

The modular multilevel converter (MMC) is an attractive topology for medium/high voltage applications with large power conversion ratings [1]-[11], because of its scalability to high operating voltages via the series connection of $2 \mathrm{~N}$ modules ( $\mathrm{N}$ per arm), its ability to operate from a single DC link without bulk bus storage capacitors, and its capability to synthesise switched waveforms with low harmonic content [3] [4]. However, since a MMC can synthesise individual output voltage levels using multiple redundant switched states, appropriate selection of these states is required to simultaneously meet the three essential requirements of maintaining balance of the individual module DC link voltages [4] [5], evenly distributing device switching losses over each fundamental cycle [4], and minimising the circulating currents that flow between the upper and lower MMC arms of each phase leg to reduce device conduction and commutation loss [4] [5]. These competing requirements make modulation of a MMC a complex task, particularly when using the harmonically superior three-phase level-shifted phase disposition modulation (PD-PWM) [12].

PD-PWM switching signals are synthesised by comparing a fundamental sinusoidal reference against $\mathrm{N}$ smaller magnitude triangular carriers arranged continuously across the linear modulation range. This scheme is well-known to achieve the best possible converter line-to-line output voltage spectrum because significant energy is put into the first carrier harmonic, which is co-phasal between the phase legs of a three-phase system [12]. However, since PD-PWM does not differentiate between redundant switched states [13], it requires post modulation state selection to equally distribute switching events across all module semiconductor devices, and to control the converter phase leg circulating currents [14]. With this approach, MMCs can generate switched output voltages with $2 \mathrm{~N}+1$ levels using nearly all possible redundant states, or $\mathrm{N}+1$ voltage levels when only a reduced set of redundant states are used.

Synthesis of optimal PD $(2 \mathrm{~N}+1$ or $\mathrm{N}+1)$ switched output voltage levels for a MMC requires integrated scheduling of the individual module switching events for both arms [14]. In addition, for the $2 \mathrm{~N}+1 \mathrm{PD}$ scheme the redundant switched states must be carefully sequenced by the post modulator decoder to avoid disrupting the phase leg high-frequency circulating currents, particularly during band transitioning processes [13]. In contrast, for PD synthesis of $\mathrm{N}+1$ switched output voltage levels, any form of round-robin redundant state sequencing is satisfactory, since the subset of redundant states used by this scheme has no effect on the phase leg circulating current. Based on these concepts, this paper presents design principles for developing $2 \mathrm{~N}+1$ and $\mathrm{N}+1$ PD-PWM finite state machine decoders for modular multilevel converters. The work has been verified by simulations and experimental investigations on a $\mathrm{N}=2 \mathrm{MMC}$.

\section{EFFECT OF PHASE LEG SWITCHING ON MMC Circulating CurRent}

The circuit topology of an exemplar MMC phase leg with two modules per arm is shown in Fig. 1. The overall converter phase leg consists of upper and lower arms, each formed by the series connection of two identical modules, with each arm linked to the phase leg output through an inductor. The individual modules have a complementary switch pair and a floating capacitor, which under steady-state balanced conditions is charged to $\mathrm{V}_{\mathrm{dc}} / 2$. For generality, the arm inductors are considered as coupled (i.e. built on a common magnetic core) with winding leakage and mutual inductances $\mathrm{L}_{\mathrm{k}}$ and $\mathrm{L}_{\mathrm{b}}$, and a small series resistance $\mathrm{R}_{\mathrm{b}}$ per winding.

Table I shows the 16 possible phase leg switched states, denoted as $\mathrm{C}_{\mathrm{i} \text {,hex }}$ for $\mathrm{i}=\{0,1,2, \ldots, 9, \mathrm{~A}, \mathrm{~B}, \ldots, \mathrm{F}\}$, that are defined by the binary combinations of the four individual converter module switching states defined by $\sigma_{i, b i n}$, for 


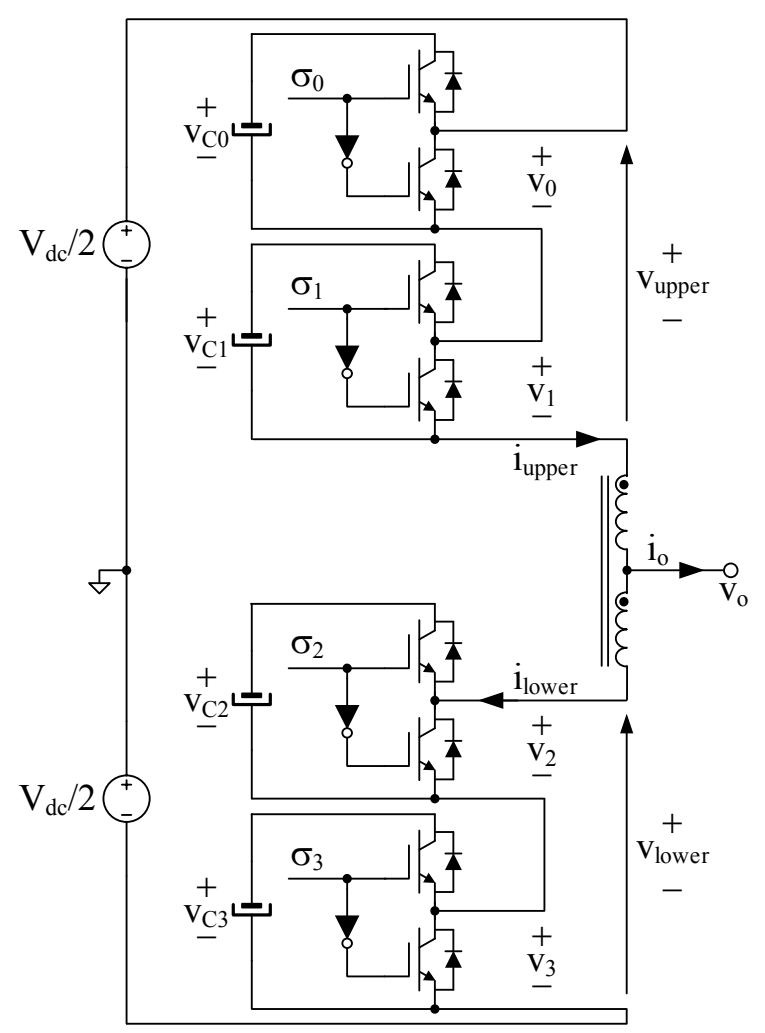

Fig. 1: MMC phase leg with $\mathrm{N}=2$.

$\mathrm{i}=\{0,1,2,3\}$ (i.e. $\mathrm{C}_{\mathrm{i} \text {, hex }}=\sigma_{3 \text {,bin }} \sigma_{2 \text {,bin }} \sigma_{1, \text { bin }} \sigma_{0 \text {,bin }}$ ). This table also shows the consequential individual module switched voltages $v_{i}=\sigma_{i}\left(V_{d c} / 2\right)$ for $i=\{0,1,2,3\}$, the resulting upper and lower arm voltages $\mathrm{v}_{\text {upper }}=\left(\mathrm{v}_{0}+\mathrm{v}_{1}\right)$ and $\mathrm{v}_{\text {lower }}=\left(\mathrm{v}_{2}+\mathrm{v}_{3}\right)$, and the common-mode and differential-mode (output) voltages $\mathrm{v}_{\mathrm{cm}}=\left(\mathrm{v}_{\text {lower }}+\mathrm{v}_{\text {upper }}\right) / 2$ and $\mathrm{v}_{\mathrm{dm}}=\mathrm{v}_{\mathrm{o}}=\left(\mathrm{v}_{\text {lower }}-\mathrm{v}_{\text {upper }}\right) / 2$.

From [6] [7] [14], the common-mode circulating current flowing through the converter phase leg is controlled by the voltage difference between the upper-half overall dc link voltage and common-mode voltage across the coupled-inductor, viz:

$$
\mathrm{i}_{\mathrm{cm}} \approx \frac{1}{\left(\mathrm{~L}_{\mathrm{k}}+2 \mathrm{~L}_{\mathrm{b}}\right)} \int\left(\mathrm{V}_{\mathrm{dc}} / 2-\mathrm{v}_{\mathrm{cm}}\right) \mathrm{dt} .
$$

Depending on this common-mode voltage, the circulating current will vary between remaining constant when $\mathrm{v}_{\mathrm{cm}}=\mathrm{V}_{\mathrm{dc}} / 2$, increasing at a given slope when $\mathrm{v}_{\mathrm{cm}}=\mathrm{V}_{\mathrm{dc}} / 4$, decreasing at the same slope when $\mathrm{v}_{\mathrm{cm}}=3 \mathrm{~V}_{\mathrm{dc}} / 4$, and increasing or decreasing at twice that slope when $\mathrm{v}_{\mathrm{cm}}=0 \mathrm{~V}$ or $\mathrm{v}_{\mathrm{cm}}=\mathrm{V}_{\mathrm{dc}}$, respectively. This information is also illustrated graphically in the $i_{\mathrm{cm}}$ column in Table I.

From Table I, there are 4 converter states available to produce the output voltage level $\mathrm{L}_{3}$ (i.e. $\mathrm{v}_{\mathrm{o}}=\mathrm{V}_{\mathrm{dc}} / 4$ ). Two of them generate a positive slope for the circulating current (states $\mathrm{C}_{4}$ and $\mathrm{C}_{8}$ ), and two create a negative slope for the circulating current (states $\mathrm{C}_{\mathrm{D}}$ and $\mathrm{C}_{\mathrm{E}}$ ). Similarly, the output voltage level $\mathrm{L}_{1}$ (i.e. $\mathrm{v}_{\mathrm{o}}=-\mathrm{V}_{\mathrm{dc}} / 4$ ) can be synthesised by 4 different converter states, two of them producing a positive slope on the circulating current (states $\mathrm{C}_{1}$ and $\mathrm{C}_{2}$ ) and two generating a negative slope on the circulating current (states $\mathrm{C}_{7}$ and $\mathrm{C}_{\mathrm{B}}$ ). Also from Table I, there are 6 redundant converter states available to generate a zero output voltage (states $\mathrm{C}_{0}$, $\mathrm{C}_{5}, \mathrm{C}_{6}, \mathrm{C}_{9}, \mathrm{C}_{\mathrm{A}}$, and $\mathrm{C}_{\mathrm{F}}$ ). Two of them cause a large positive or a large negative circulating current slope (states $\mathrm{C}_{0}$ and $\mathrm{C}_{\mathrm{F}}$, respectively), while for the other 4 redundant zero output voltage states the circulating current remains constant.

\section{DeCODER REQUiREMENTS FOR MMC CONVERTERS}

Since PD-PWM does not select between the various converter redundant states shown in Table I, the switching command signals synthesised by this modulation scheme must be post manipulated by a decoding structure. This can be done

TABle I: EfFect of Phase Leg Switched States on the Common- AND Differential-Mode Quantities

\begin{tabular}{|c|c|c|c|c|c|c|c|c|c|c|c|c|c|c|}
\hline C & $\sigma_{3}$ & $\sigma_{2}$ & $\sigma_{1}$ & $\sigma_{0}$ & $\mathbf{v}_{3}$ & $\mathbf{v}_{2}$ & $\mathbf{v}_{1}$ & $\mathbf{v}_{\mathbf{0}}$ & $\mathbf{V}_{\text {lower }}$ & $\mathbf{V}_{\text {upper }}$ & Level & $\mathbf{v}_{\mathrm{dm}}=\mathbf{v}_{\mathbf{0}}$ & $\mathbf{v}_{\mathrm{cm}}$ & $\mathbf{i}_{\mathrm{cm}}$ \\
\hline $\mathrm{C}_{\mathrm{C}}$ & 1 & 1 & 0 & 0 & $\mathrm{~V}_{\mathrm{dc}} / 2$ & $\mathrm{~V}_{\mathrm{dc}} / 2$ & 0 & 0 & $\mathrm{~V}_{\mathrm{dc}}$ & 0 & $\mathrm{~L}_{4}$ & $\mathrm{~V}_{\mathrm{dc}} / 2$ & $\mathrm{~V}_{\mathrm{dc}} / 2$ & \\
\hline $\mathrm{C}_{8}$ & 1 & 0 & 0 & 0 & $\mathrm{~V}_{\mathrm{dc}} / 2$ & 0 & 0 & 0 & $\mathrm{~V}_{\mathrm{dc}} / 2$ & 0 & $\mathrm{~L}_{3}$ & $\mathrm{~V}_{\mathrm{dc}} / 4$ & $\mathrm{~V}_{\mathrm{dd}} / 4$ & \\
\hline $\mathrm{C}_{4}$ & 0 & 1 & 0 & 0 & 0 & $\mathrm{~V}_{\mathrm{dc}} / 2$ & 0 & 0 & $\mathrm{~V}_{\mathrm{dc}} / 2$ & 0 & $\mathrm{~L}_{3}$ & $\mathrm{~V}_{\mathrm{dd}} / 4$ & $\mathrm{~V}_{\mathrm{dc}} / 4$ & \\
\hline $\mathrm{C}_{\mathrm{E}}$ & 1 & 1 & 1 & 0 & $\mathrm{~V}_{\mathrm{dc}} / 2$ & $\mathrm{~V}_{\mathrm{dc}} / 2$ & $\mathrm{~V}_{\mathrm{dc}} / 2$ & 0 & $\mathrm{~V}_{\mathrm{dc}}$ & $\mathrm{V}_{\mathrm{dc}} / 2$ & $\mathrm{~L}_{3}$ & $\mathrm{~V}_{\mathrm{dc}} / 4$ & $3 \mathrm{~V}_{\mathrm{dc}} / 4$ & \\
\hline $\mathrm{C}_{\mathrm{D}}$ & 1 & 1 & 0 & 1 & $\mathrm{~V}_{\mathrm{dc}} / 2$ & $\mathrm{~V}_{\mathrm{dc}} / 2$ & 0 & $\mathrm{~V}_{\mathrm{dc}} / 2$ & $\mathrm{~V}_{\mathrm{dc}}$ & $\mathrm{V}_{\mathrm{dc}} / 2$ & $\mathrm{~L}_{3}$ & $\mathrm{~V}_{\mathrm{dc}} / 4$ & $3 \mathrm{~V}_{\mathrm{dc}} / 4$ & \\
\hline $\mathrm{C}_{0}$ & 0 & 0 & 0 & 0 & 0 & 0 & 0 & 0 & 0 & 0 & $\mathrm{~L}_{2}$ & 0 & 0 & \\
\hline $\mathrm{C}_{\mathrm{A}}$ & 1 & 0 & 1 & 0 & $\mathrm{~V}_{\mathrm{dc}} / 2$ & 0 & $\mathrm{~V}_{\mathrm{dd}} / 2$ & 0 & $\mathrm{~V}_{\mathrm{dc}} / 2$ & $\mathrm{~V}_{\mathrm{dd}} / 2$ & $\mathrm{~L}_{2}$ & 0 & $\mathrm{~V}_{\mathrm{dc}} / 2$ & \\
\hline $\mathrm{C}_{6}$ & 0 & 1 & 1 & 0 & 0 & $\mathrm{~V}_{\mathrm{dc}} / 2$ & $\mathrm{~V}_{\mathrm{dc}} / 2$ & 0 & $\mathrm{~V}_{\mathrm{dc}} / 2$ & $\mathrm{~V}_{\mathrm{dc}} / 2$ & $\mathrm{~L}_{2}$ & 0 & $\mathrm{~V}_{\mathrm{dc}} / 2$ & \\
\hline $\mathrm{C}_{9}$ & 1 & 0 & 0 & 1 & $\mathrm{~V}_{\mathrm{dc}} / 2$ & 0 & 0 & $\mathrm{~V}_{\mathrm{dc}} / 2$ & $\mathrm{~V}_{\mathrm{dc}} / 2$ & $\mathrm{~V}_{\mathrm{dc}} / 2$ & $\mathrm{~L}_{2}$ & 0 & $\mathrm{~V}_{\mathrm{dc}} / 2$ & \\
\hline $\mathrm{C}_{5}$ & 0 & 1 & 0 & 1 & 0 & $\mathrm{~V}_{\mathrm{dc}} / 2$ & 0 & $\mathrm{~V}_{\mathrm{dc}} / 2$ & $\mathrm{~V}_{\mathrm{dc}} / 2$ & $\mathrm{~V}_{\mathrm{dc}} / 2$ & $\mathrm{~L}_{2}$ & 0 & $\mathrm{~V}_{\mathrm{dc}} / 2$ & \\
\hline $\mathrm{C}_{\mathrm{F}}$ & 1 & 1 & 1 & 1 & $\mathrm{~V}_{\mathrm{dc}} / 2$ & $\mathrm{~V}_{\mathrm{dc}} / 2$ & $\mathrm{~V}_{\mathrm{dd}} / 2$ & $\mathrm{~V}_{\mathrm{dc}} / 2$ & $\mathrm{~V}_{\mathrm{dc}}$ & $\mathrm{V}_{\mathrm{dc}}$ & $\mathrm{L}_{2}$ & 0 & $\mathrm{~V}_{\mathrm{dc}}$ & \\
\hline $\mathrm{C}_{2}$ & 0 & 0 & 1 & 0 & 0 & 0 & $\mathrm{~V}_{\mathrm{dd}} / 2$ & 0 & 0 & $\mathrm{~V}_{\mathrm{dc}} / 2$ & $\mathrm{~L}_{1}$ & $-\mathrm{V}_{\mathrm{dc}} / 4$ & $\mathrm{~V}_{\mathrm{dc}} / 4$ & \\
\hline $\mathrm{C}_{1}$ & 0 & 0 & 0 & 1 & 0 & 0 & 0 & $\mathrm{~V}_{\mathrm{dc}} / 2$ & 0 & $\mathrm{~V}_{\mathrm{dc}} / 2$ & $\mathrm{~L}_{1}$ & $-\mathrm{V}_{\mathrm{dc}} / 4$ & $\mathrm{~V}_{\mathrm{dc}} / 4$ & \\
\hline $\mathrm{C}_{\mathrm{B}}$ & 1 & 0 & 1 & 1 & $\mathrm{~V}_{\mathrm{dc}} / 2$ & 0 & $\mathrm{~V}_{\mathrm{dc}} / 2$ & $\mathrm{~V}_{\mathrm{dc}} / 2$ & $\mathrm{~V}_{\mathrm{dc}} / 2$ & $\mathrm{~V}_{\mathrm{dc}}$ & $\mathrm{L}_{1}$ & $-\mathrm{V}_{\mathrm{dc}} / 4$ & $3 \mathrm{~V}_{\mathrm{dc}} / 4$ & \\
\hline $\mathrm{C}_{7}$ & 0 & 1 & 1 & 1 & 0 & $\mathrm{~V}_{\mathrm{dc}} / 2$ & $\mathrm{~V}_{\mathrm{dc}} / 2$ & $\mathrm{~V}_{\mathrm{dc}} / 2$ & $\mathrm{~V}_{\mathrm{dc}} / 2$ & $\mathrm{~V}_{\mathrm{dc}}$ & $\mathrm{L}_{1}$ & $-\mathrm{V}_{\mathrm{dc}} / 4$ & $3 \mathrm{~V}_{\mathrm{dc}} / 4$ & \\
\hline $\mathrm{C}_{3}$ & 0 & 0 & 1 & 1 & 0 & 0 & $\mathrm{~V}_{\mathrm{dc}} / 2$ & $\mathrm{~V}_{\mathrm{dc}} / 2$ & 0 & $\mathrm{~V}_{\mathrm{dc}}$ & $\mathrm{L}_{0}$ & $-\mathrm{V}_{\mathrm{dc}} / 2$ & $\mathrm{~V}_{\mathrm{dd}} / 2$ & \\
\hline
\end{tabular}


by using a finite state machine decoder to equally distribute the switching events across all module semiconductor devices according to a given criterion [13]-[15]. In particular for the MMC topology, the decoder must additionally perform the function of controlling the converter phase leg dc level and high-frequency circulating currents.

The phase leg circulating current can be maintained at a constant dc bias level with minimum switching ripple by satisfying two essential requirements. Firstly, every time the modulator/decoder is required to produce the output voltage level $\mathrm{L}_{3}$ (i.e. $\mathrm{v}_{\mathrm{o}}=\mathrm{V}_{\mathrm{dc}} / 4$ ), this should be done on an alternating round-robin basis to select between the positive- $\mathrm{i}_{\mathrm{cm}}$-slope and negative- $i_{\mathrm{cm}}$-slope redundant states, $\left\{\mathrm{C}_{4}, \mathrm{C}_{8}\right\}$ and $\left\{\mathrm{C}_{\mathrm{D}}, \mathrm{C}_{\mathrm{E}}\right\}$, respectively, i.e. following for example the pattern $\mathrm{C}_{4} \rightarrow \mathrm{C}_{\mathrm{D}} \rightarrow \mathrm{C}_{8} \rightarrow \mathrm{C}_{\mathrm{E}}$. Similarly, for synthesis of output voltage level $L_{1}\left(\right.$ i.e. $\left.v_{o}=-V_{d c} / 4\right)$, this should be done by alternatively selecting between redundant state sets $\left\{\mathrm{C}_{1}, \mathrm{C}_{2}\right\}$ and $\left\{\mathrm{C}_{7}, \mathrm{C}_{\mathrm{B}}\right\}$, i.e. for example following the pattern $\mathrm{C}_{1} \rightarrow \mathrm{C}_{7} \rightarrow \mathrm{C}_{2} \rightarrow \mathrm{C}_{\mathrm{B}}$. Secondly, every time the modulator/decoder is commanded to produce the zero output voltage level $\mathrm{L}_{2}$, this should be done by selecting on a round-robin basis the $\mathrm{i}_{\mathrm{cm}}$-constant redundant states $\mathrm{C}_{5}, \mathrm{C}_{6}, \mathrm{C}_{9}$, and $\mathrm{C}_{\mathrm{A}}$, and avoiding the use of the two zero-output-voltage redundant states that produce the large positive/negative circulating current slopes (states $\mathrm{C}_{0}$ and $\mathrm{C}_{\mathrm{F}}$ ).

\section{Conventional (2N+1) Five-LeVel PD-PWM Decoder}

Fig. 2(a) and 2(b) show a $(2 \mathrm{~N}+1)$ five-level PD modulator with a finite state machine post modulator decoder that fulfils these requirements, built using the principles from [15]. The decoder inputs are the 4 PD-PWM logic switching signals $\mathrm{s}_{0}$, $\mathrm{s}_{1}, \mathrm{~s}_{2}$, and $\mathrm{s}_{3}$, while the decoder outputs are the gate signals $\sigma_{0}$, $\sigma_{1}, \sigma_{2}$, and $\sigma_{3}$ which drive the individual module active upper switches (lower switches are driven in a complementary fashion with the inclusion of dead-time). The finite state machine contains 32 states and 56 transitions (self-loop transitions are omitted for clarity since they do not change the output action), and its present state depends on the past output voltage level transitions $\mathrm{L}_{\mathrm{i}}, \mathrm{i}=\{0,1,2,3,4\}$.

Within a particular disposition band, this strategy produces a relatively well-behaved circulating current. However the current dc bias point does drift away during a band change transition, as shown in Fig. 2(c). This occurs because in PD-PWM the active switched pulse position is displaced by one half-carrier period when changing bands, and this causes the redundant state to become one-half-carrier period shorter just after the band transition, as highlighted in Fig. 2(c). This circulating current dc bias drift is quite undesirable since it causes low-frequency oscillations on the individual module capacitor voltages.

\section{OPTIMISED (2N+1) FIVE-LEVEL PD-PWM DECODER}

Circulating current dc bias drifts can be compensated by applying an additional redundant state selection immediately after a band transition has occurred. This is illustrated in Fig. 3. Fig. 3(a) shows the conventional scenario with the shortened redundant state at the band transition, which leads to a decrease in the circulating current bias in the next redundant state (for example the highlighted $\sigma_{3} \sigma_{2} \sigma_{1} \sigma_{0}=\{1101\}$ state

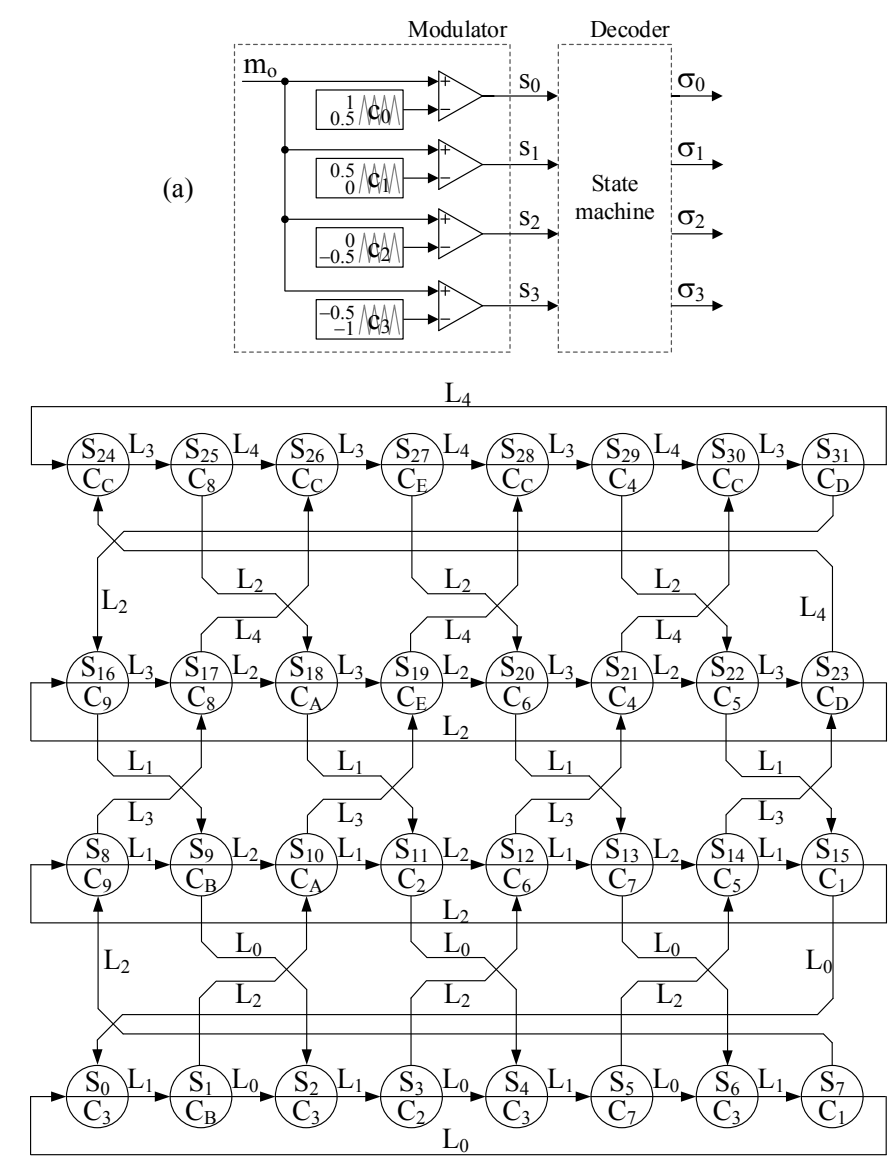

(b)

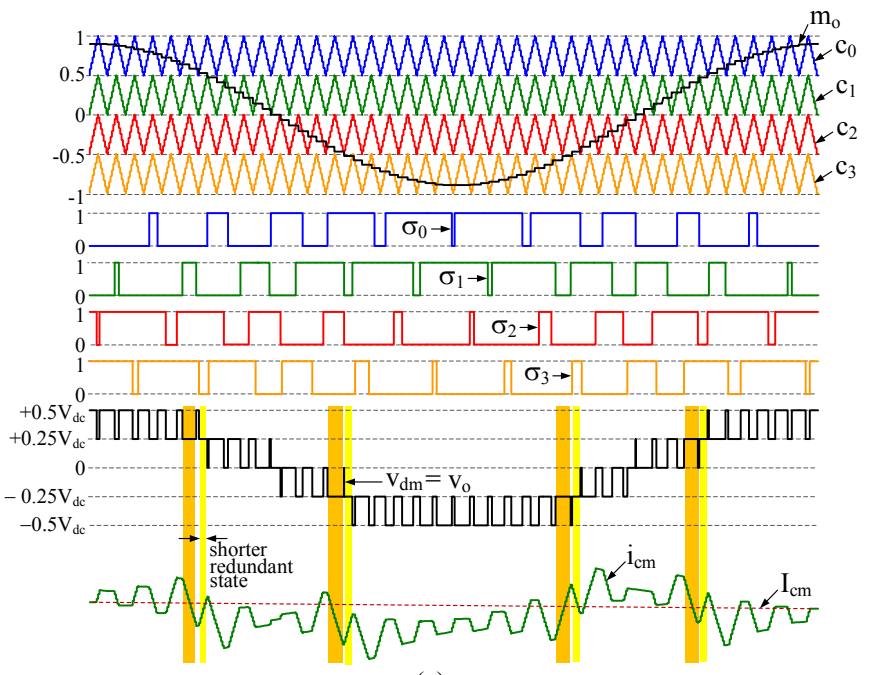

(c)

Fig. 2: Five-level PD-PWM with post modulator decoder as per reference [15]: (a) structure, (b) state machine, and (c) waveforms.

shown on the left-side of Fig. 3(a)). However this effect can be avoided by forcing a further redundant state selection (for example the change of $\sigma_{3} \sigma_{2} \sigma_{1} \sigma_{0}$ from 1101 to 0100 shown on the left-side of Fig. 3(b)) midway through the first half-carrier interval after the band transition. This additional selection compensates for the shortened redundant state at the band transition, and drives the circulating current back to its original dc operating point. 


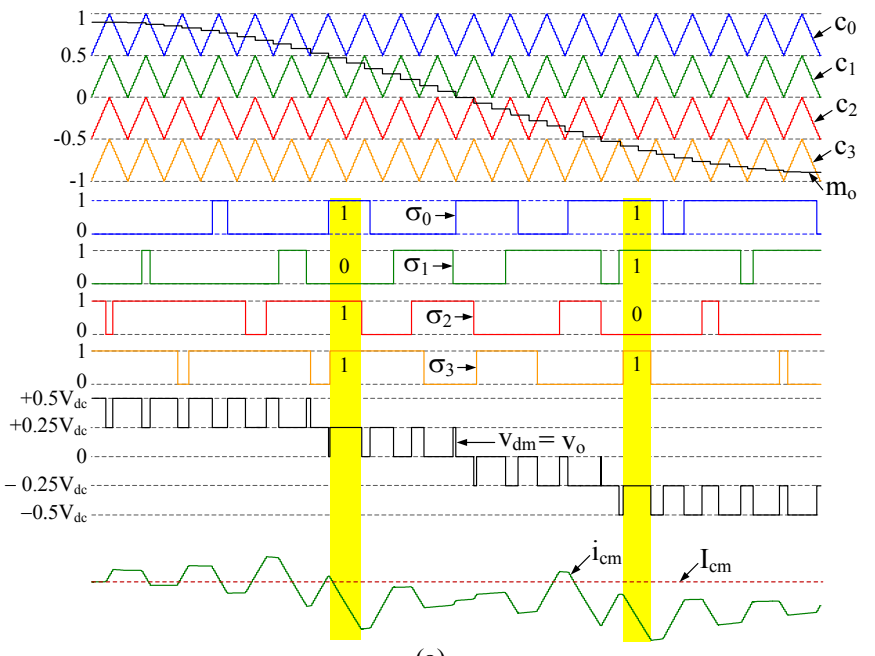

(a)

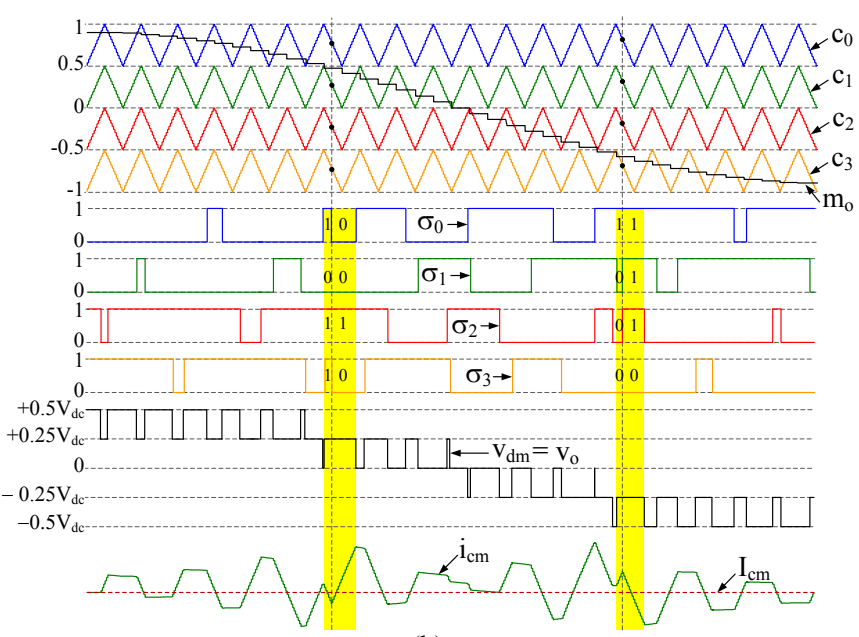

(b)

Fig. 3: Effect of band transitioning redundant state reversal on phase leg circulating current: (a) without and (b) with reversal.

Since the redundant state shortening interval is always one-half-carrier period, the timing for the additional redundant state selection should be set to be exactly midway through the half-carrier interval that follows a band transition. This is most conveniently achieved with an ancillary square wave signal $\mathrm{s}_{\mathrm{q}}$, constructed by comparing a fixed modulation reference $\mathrm{m}_{\mathrm{q}}=0.75$ against carrier $\mathrm{c}_{0}$ as shown in Fig. $4(\mathrm{a}) . \mathrm{s}_{\mathrm{q}}$ is then fed to a finite state machine decoder built upon the principles of [15] but augmented to incorporate 24 additional states for managing the band transitioning process as shown in Fig. 4(b). The decoder inputs are the 4 PD-PWM logic switching signals $\mathrm{s}_{0}, \mathrm{~s}_{1}, \mathrm{~s}_{2}$, and $\mathrm{s}_{3}$ and the square wave signal $\mathrm{s}_{\mathrm{q}}$, while the decoder outputs are the gate signals $\sigma_{0}, \sigma_{1}, \sigma_{2}$, and $\sigma_{3}$ which drive the individual MMC modules.

From Fig. 4(b), the circular path from states $S_{0}$ through to $S_{7}$ and back to $S_{0}$ defines the operation for Band 0. Similarly, circular paths from states $S_{8}$ to $S_{15}$ back to $S_{8}, S_{16}$ to $S_{23}$ back to $S_{16}$, and $S_{24}$ to $S_{31}$ back to $S_{24}$ define the operation for Bands 1,2 , and 3 , respectively. None of these paths depend on the square wave signal $\mathrm{s}_{\mathrm{q}}$ and were conceived essentially to select the redundant states on a round-robin basis as per [15]. Paths from states $S_{32}$ to $S_{34}, S_{35}$ to $S_{37}, S_{38}$ to $S_{40}$, and $S_{41}$ to $S_{43}$

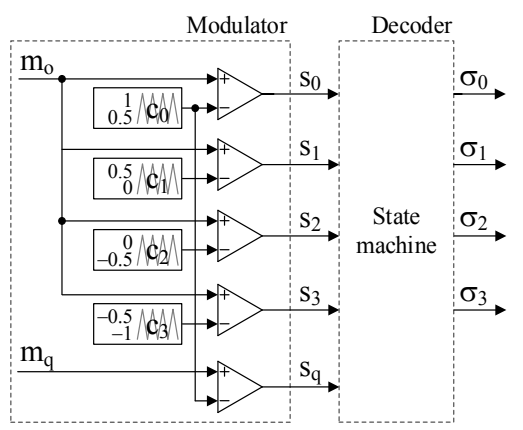

(a)
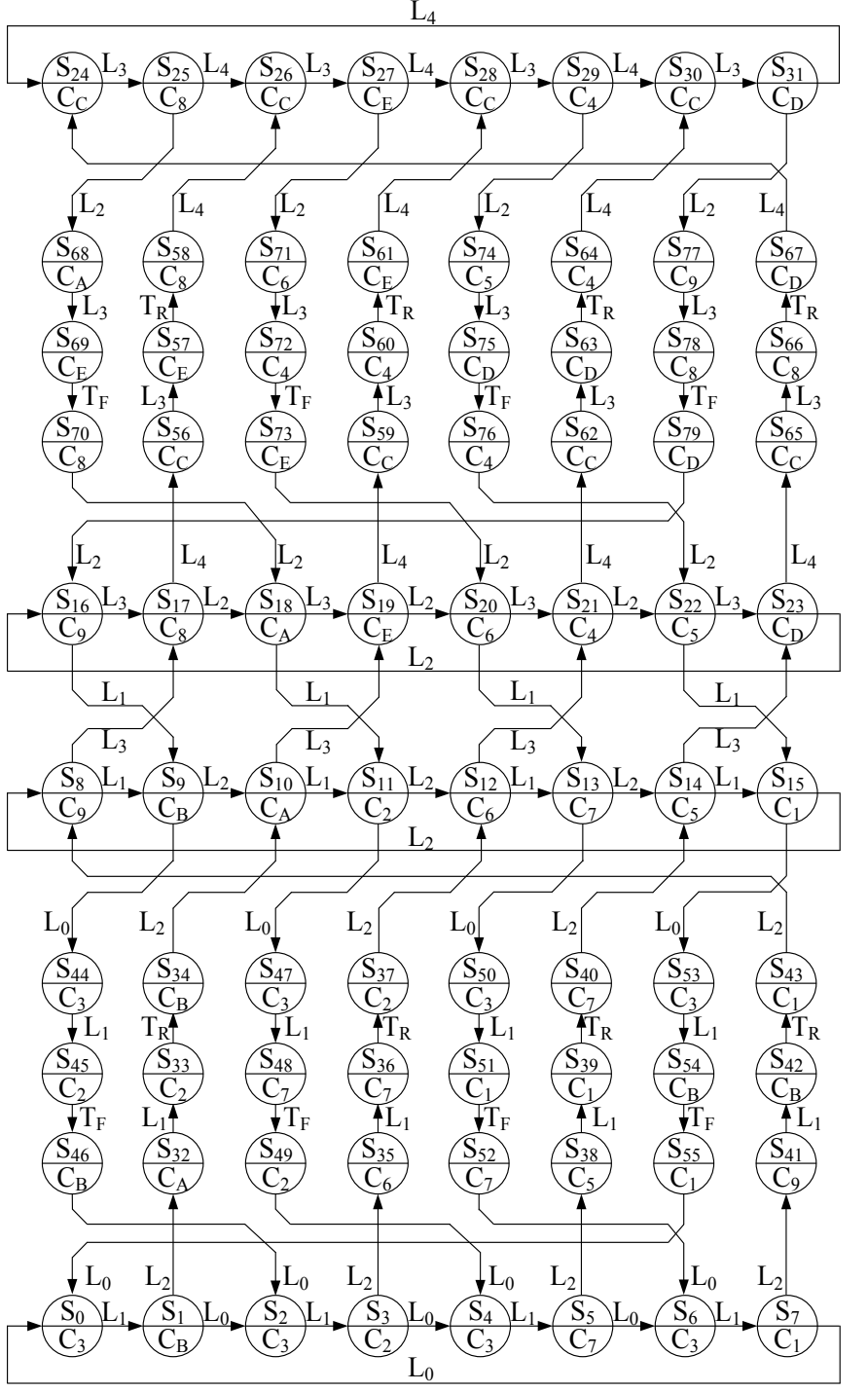

(b)

Fig. 4: Five-level PD-PWM with optimised post modulator decoder: (a) structure, (b) state machine, and (c) waveforms.

dictate the behaviour when moving from Band 0 to Band 1, and paths from states $S_{44}$ to $S_{46}, S_{47}$ to $S_{49}, S_{50}$ to $S_{52}$, and $S_{53}$ to $S_{55}$ define the behaviour when moving from Band 1 to Band 0 . Both paths reverse the slope of the circulating current midway through the band transition event, using changes on the square wave signal $\mathrm{s}_{\mathrm{q}}$ as a timing generator for the slope reversal. Similar paths manage the transitions from Bands 2 to 
3 and vice-versa, however paths from Bands 1 to 2 and 2 to 1 do not incorporate additional states, since the band transitioning drift on the circulating current dc bias is very small for those band changes as shown in Fig. 3(b).

State machine decoders for MMCs with higher number of cells per arm can be developed following the same approach as exemplified in this paper for the particular case of two cells per arm. In general, for a MMC with $\mathrm{N}$ cells per arm, the decoder structure consists of $2 \mathrm{~N}$ rows corresponding to each PWM disposition band, each with $4 \mathrm{~N}$ logical states to account for the total number of phase leg sub-modules (i.e. $2 \mathrm{~N}$ ) and the two switching events produced within each carrier interval. Within this structure, sub-module switched states are then allocated to their relevant row for a given disposition band, in a sequence that balances the usage of upper and lower arm sub-module devices while simultaneously achieving cycle-by-cycle reversal of the common-mode voltage to constrain the circulating current. In addition, the decoder arrangement also contains $4 \mathrm{~N}$ triplets of states for each disposition band to specifically constrain the common-mode current during a band change, except for the central disposition band where a direct transitioning between bands

(a)

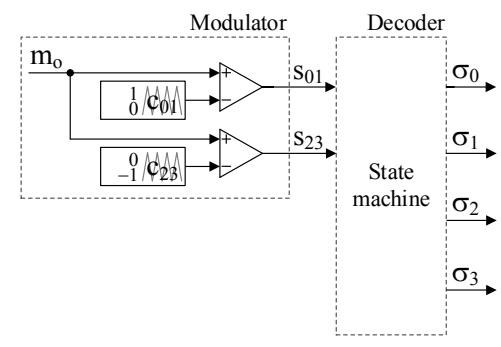

$\mathrm{L}_{2}$

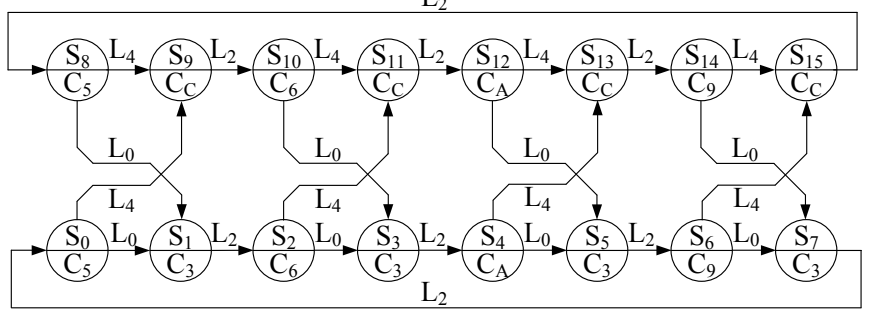

(b)

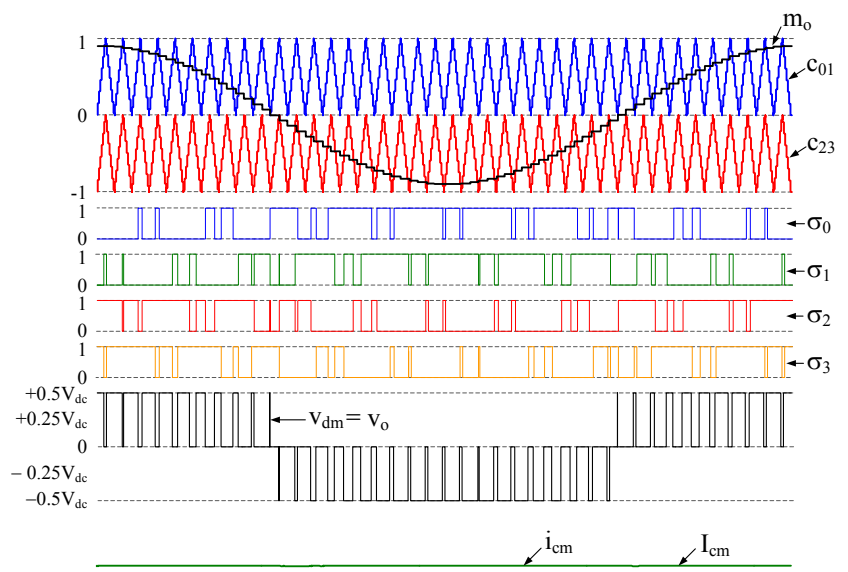

(c)

Fig. 5: Three-level PD-PWM decoder: (a) structure, (b) state machine, and (c) waveforms. (i.e. without the circulating current slope reversal midway through the band transition event) causes minimal disturbance to the common-mode current.

\section{SIMPLIFICATION FOR (N+1) THREE-LEVEL PD-PWM}

Inspection of Table I indicates that for the set of switched states responsible for the synthesis of levels $\mathrm{L}_{0}, \mathrm{~L}_{2}$, and $\mathrm{L}_{4}$, the common-mode current remains constant (except for the unused states $\mathrm{C}_{0}$ and $\mathrm{C}_{\mathrm{F}}$ ), whereas for the switching states that produce levels $\mathrm{L}_{1}$ and $\mathrm{L}_{3}$, the circulating current presents varied slopes according to the selected redundant state. Hence

a much simpler decoder can be developed for implementing $(\mathrm{N}+1)$ three-level PD-PWM for MMCs that readily produces a common-mode current free of high frequency components, by avoiding the use of switching states that produce levels $\mathrm{L}_{1}$ and $\mathrm{L}_{3}$. Fig. 5(a) shows the modulator/decoder structure, where two three-level PD logic switching signals $\mathrm{s}_{01}$ and $\mathrm{s}_{23}$, synthesised by comparing a sinusoidal reference $\mathrm{m}_{\mathrm{o}}$ with two level-shifted carriers $\mathrm{c}_{01}$ and $\mathrm{c}_{23}$, are fed to a post modulator decoder to generate the 4 gate signals $\sigma_{0}, \sigma_{1}, \sigma_{2}$, and $\sigma_{3}$ which drive the individual modules. The finite state machine arrangement is shown Fig. 5(b), with resulting waveforms presented in Fig. 5(c), showing a constant circulating current at the dc bias level as expected.

In general, for a MMC with $\mathrm{N}$ cells per arm, the decoder structure has $\mathrm{N}$ rows corresponding to each PWM disposition band, each with 4N logical states to account for the total number of phase leg sub-modules (i.e. $2 \mathrm{~N}$ ) and the two switching events produced within each carrier interval. Within this structure, sub-module switched states are allocated to their relevant row for a given disposition band, in a sequence that balances usage of upper and lower arm sub-module devices.

\section{SIMULATION AND EXPERIMENTAL RESULTS}

The concepts presented in this paper have been validated using detailed PSIM switching models, and a prototype $\mathrm{N}=2$ MMC phase leg with parameters as listed in Table II. A Texas Instruments TMS320F2812 processor was used for the PWM generation and the post modulation decoding schemes were implemented on an Altera MAX-II EPM570T100C5 CPLD.

TABLE II: SYSTEM PARAMETERS

\begin{tabular}{l|c|c}
\hline \multicolumn{1}{c|}{ Description } & Label & Value \\
\hline \hline Number of modules per arm & $\mathrm{N}$ & 2 \\
\hline dc-link voltage & $\mathrm{V}_{\mathrm{dc}}$ & $400 \mathrm{~V}$ \\
\hline Fundamental frequency & $\mathrm{f}_{\mathrm{o}}$ & $50 \mathrm{~Hz}$ \\
\hline Individual module switching frequency & $\mathrm{f}_{\mathrm{m}}$ & $500 \mathrm{~Hz}$ \\
\hline Effective switching frequency & $\mathrm{f}_{\mathrm{c}}$ & $2 \mathrm{kHz}$ \\
\hline Modulation depth & $\mathrm{M}$ & 0.9 \\
\hline Individual module bus capacitors & $\mathrm{C}_{\mathrm{dc}}$ & $2,700 \mu \mathrm{F}$ \\
\hline Coupled-inductor & & \\
Self-inductance & $\mathrm{L}$ & $2.0 \mathrm{mH}$ \\
Leakage-inductance & $\mathrm{L}_{\mathrm{k}}$ & $0.1 \mathrm{mH}$ \\
Mutual-inductance & $\mathrm{L}_{\mathrm{b}}$ & $1.9 \mathrm{mH}$ \\
Individual winding-resistance & $\mathrm{R}_{\mathrm{w}}$ & $50 \mathrm{~m} \Omega$ \\
\hline Load resistance & & $19.2 \Omega$ \\
\hline Load inductance & & $4.1 \mathrm{mH}$ \\
\hline
\end{tabular}


Fig. 6 presents simulation waveforms for the five-level PD MMC modulation with optimized post modulator decoding as per Fig. 4. More specifically, Fig. 6(a) shows the phase leg output voltage $\mathrm{v}_{\mathrm{o}}$ with the anticipated five distinct voltage levels (the slight level slope is caused by low frequency ripple in the sub-module dc-link voltages). Fig. 6(b) shows the upper and lower arm currents, $i_{\text {upper }}$ and $i_{\text {lower }}$, respectively, and Fig. 6(c) shows the resulting common-mode (circulating) current $\mathrm{i}_{\mathrm{cm}}=\left(\mathrm{i}_{\text {upper }}+\mathrm{i}_{\text {lower }}\right) / 2$ and differential-mode (output) current

(a)
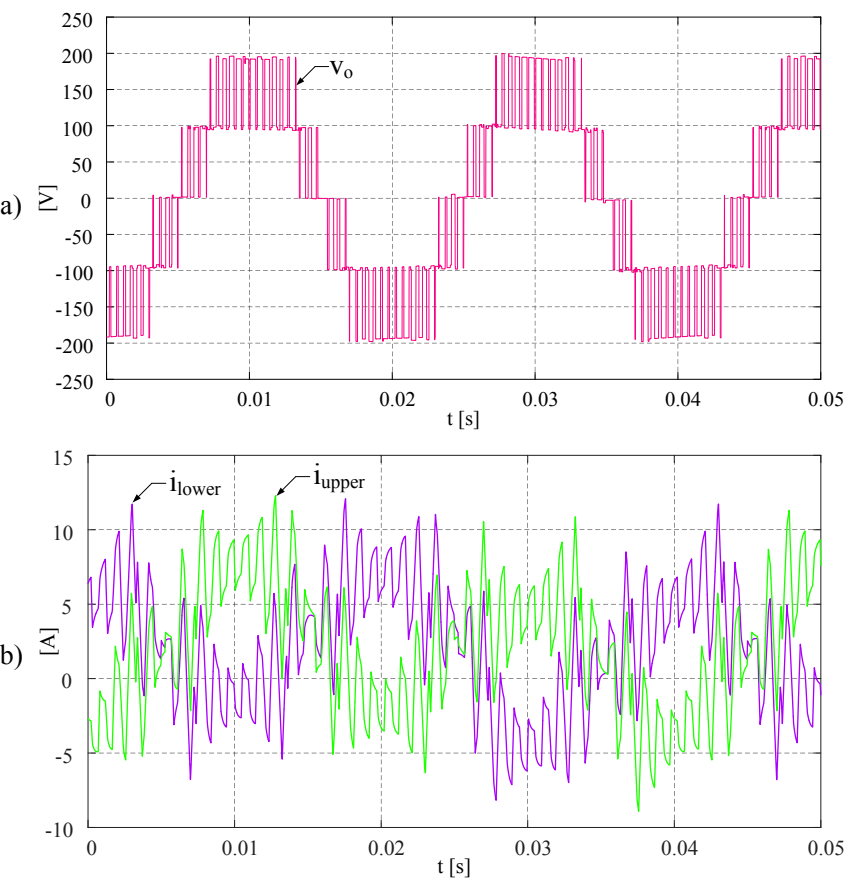

(c)
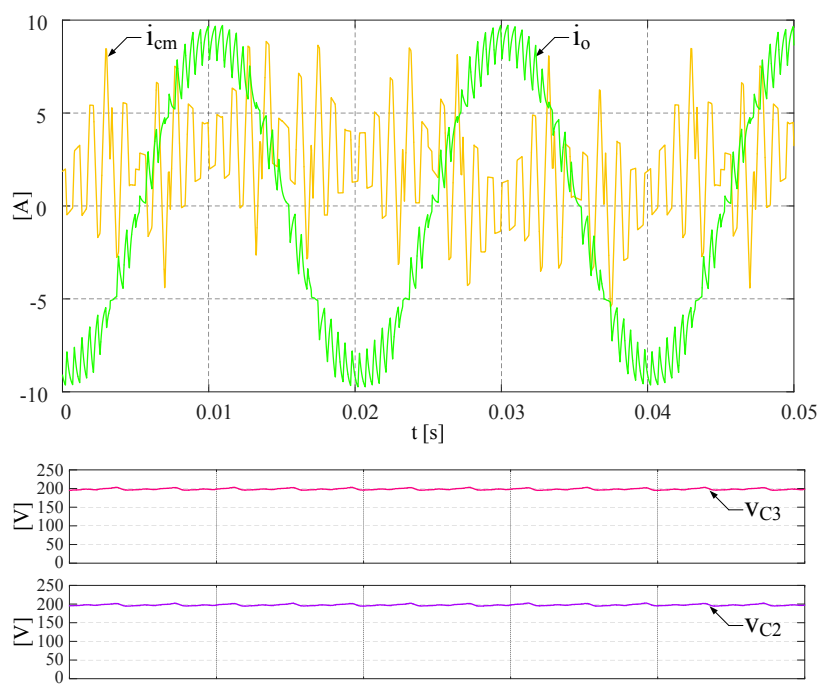

(d)

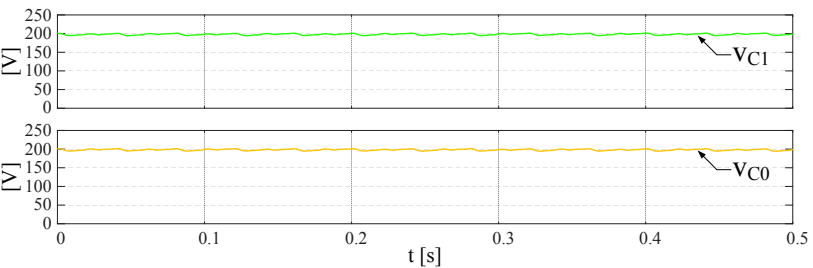

Fig. 6: Simulation results for five-level PD-PWM decoder: (a) switched output voltage $v_{\mathrm{o}}$, (b) arm currents $i_{\text {upper, }} i_{\text {lower }}$, (c) circulating current $i_{\mathrm{cm}}$ and output current $\mathrm{i}_{\mathrm{o}}$, (d) individual module capacitor voltages $\mathrm{v}_{\mathrm{C} 0}, \mathrm{v}_{\mathrm{C} 1}, \mathrm{v}_{\mathrm{C} 2}, \mathrm{v}_{\mathrm{C} 3}$. $i_{d m}=\left(i_{\text {upper }}-i_{\text {lower }}\right) / 2=i_{0} / 2$. From Fig. $6(c)$, the common-mode current $i_{\mathrm{cm}}$ is well behaved and operates around a bias level (note that besides containing a dc component $\mathrm{I}_{\mathrm{cm}}$ it also has a low frequency oscillation as a consequence of sub-modules dc-link voltage ripple). Finally, Fig. 6(d) shows that the state machine decoder is able to achieve natural balancing of the module capacitor voltages $\left(\mathrm{v}_{\mathrm{C} 0}\right.$ through to $\left.\mathrm{v}_{\mathrm{C} 3}\right)$ as desired.

(a)

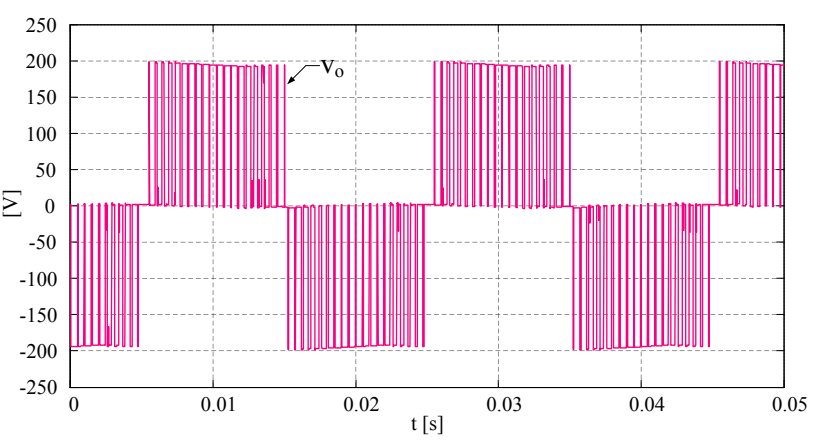

(b)

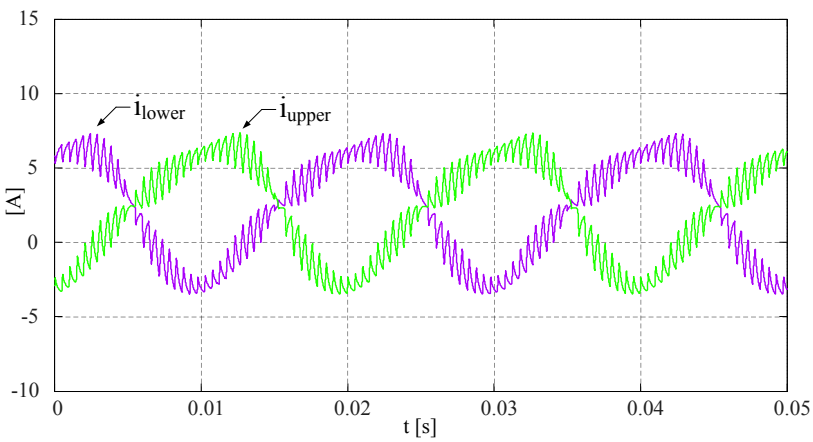

(c)
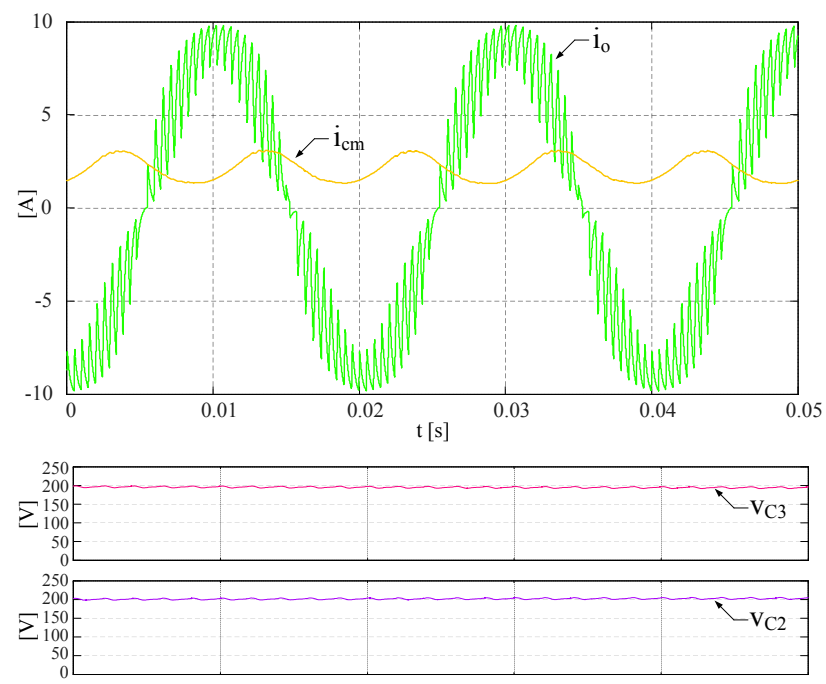

(d)

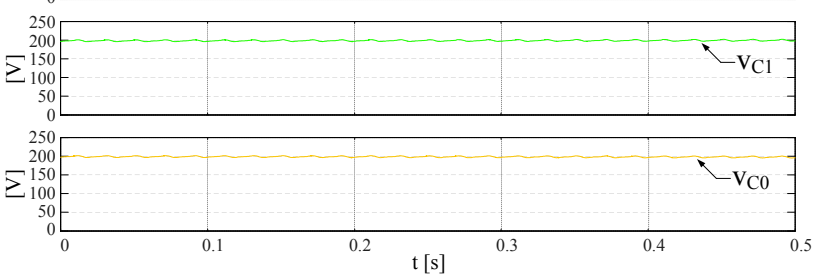

Fig. 7: Simulation results for three-level PD-PWM decoder: (a) switched output voltage $\mathrm{v}_{\mathrm{o}}$, (b) arm currents $\mathrm{i}_{\text {upper, }}, \mathrm{i}_{\text {lower }}$, (c) circulating current $\mathrm{i}_{\mathrm{cm}}$ and output current $\mathrm{i}_{\mathrm{o}}$, (d) individual module capacitor voltages $\mathrm{v}_{\mathrm{C} 0}, \mathrm{v}_{\mathrm{C} 1}, \mathrm{v}_{\mathrm{C} 2}, \mathrm{v}_{\mathrm{C} 3}$. 


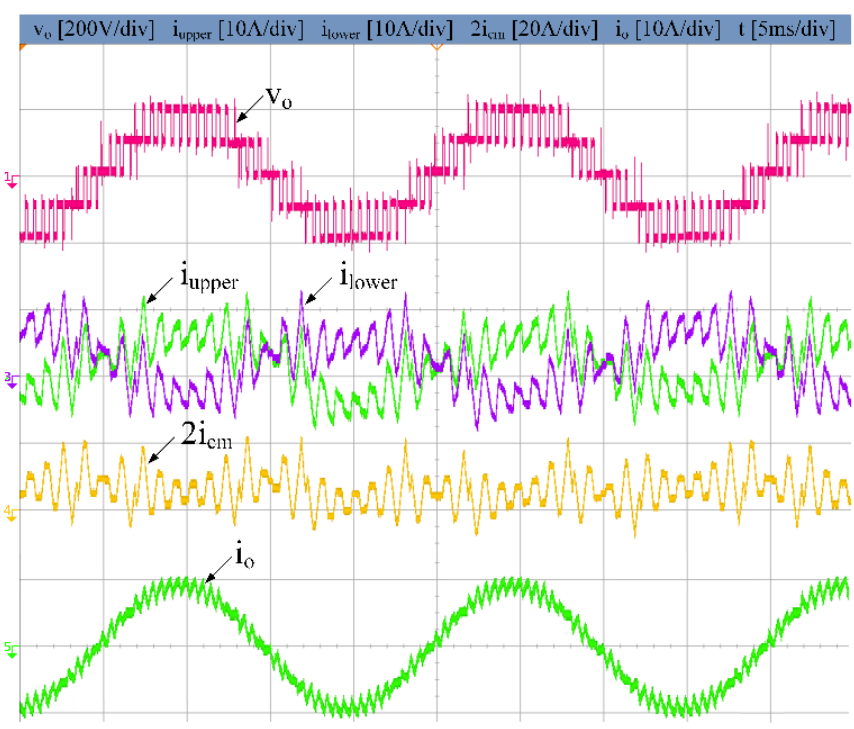

(a)

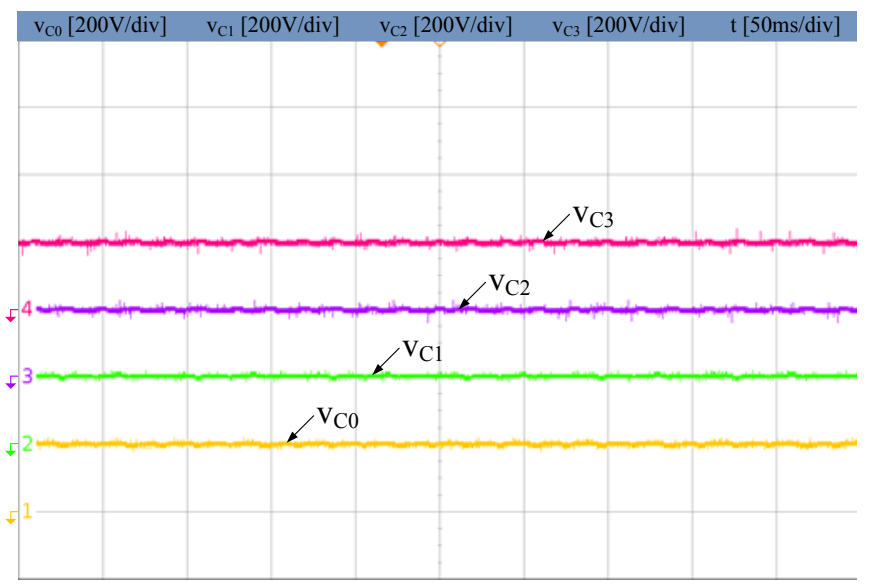

(b)

Fig. 8: Experimental results for five-level PD-PWM decoder: (a) switched output voltage $v_{0}$, arm currents $i_{\text {upper }}$ and $i_{\text {lower }}$, circulating current $i_{\text {cm }}$, and output current $\mathrm{i}_{\mathrm{o}}$, (b) individual module capacitor voltages $\mathrm{v}_{\mathrm{C} 0}, \mathrm{v}_{\mathrm{C} 1}, \mathrm{v}_{\mathrm{C} 2}, \mathrm{v}_{\mathrm{C} 3}$.

Fig. 7 shows simulation plots for the MMC three-level PD-PWM with simplified decoder as per Fig. 5. In particular, Fig. 7(a) shows the phase leg switched output voltage $v_{0}$ (in this case with three definite voltage levels), Fig. 7(b) shows the upper and lower arm currents, $i_{\text {upper }}$ and $i_{\text {lower }}$, respectively, and Fig. 7(c) shows the circulating and output currents, $i_{\mathrm{cm}}$ and $i_{o}$, respectively. From Fig. 7(c), the common-mode current $i_{c m}$ is now free of high frequency components and only contains the dc bias plus low frequency oscillation, while the output current $i_{o}$ presents higher ripple magnitude as expected. Fig. 7(d) shows that also for the simplified decoder, natural balancing of the module capacitor voltages is achieved.

Matching experimental results for the five-level optimized PD-PWM decoder and for the simplified three-level PD-PWM decoder, are presented in Figs. 8 and 9, respectively, confirming the practical viability of these two approaches. In addition, Figs. 10 and 11 present the simulated and experimental MMC phase voltage spectrum achieved with these two decoding techniques, which both clearly show the large dominant carrier harmonic expected for PD-PWM

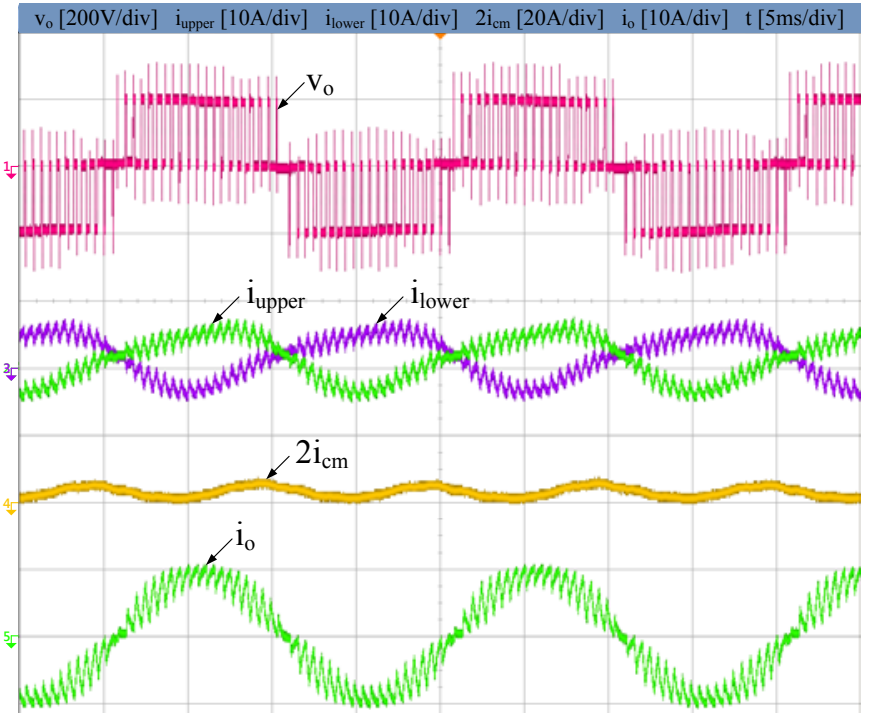

(a)

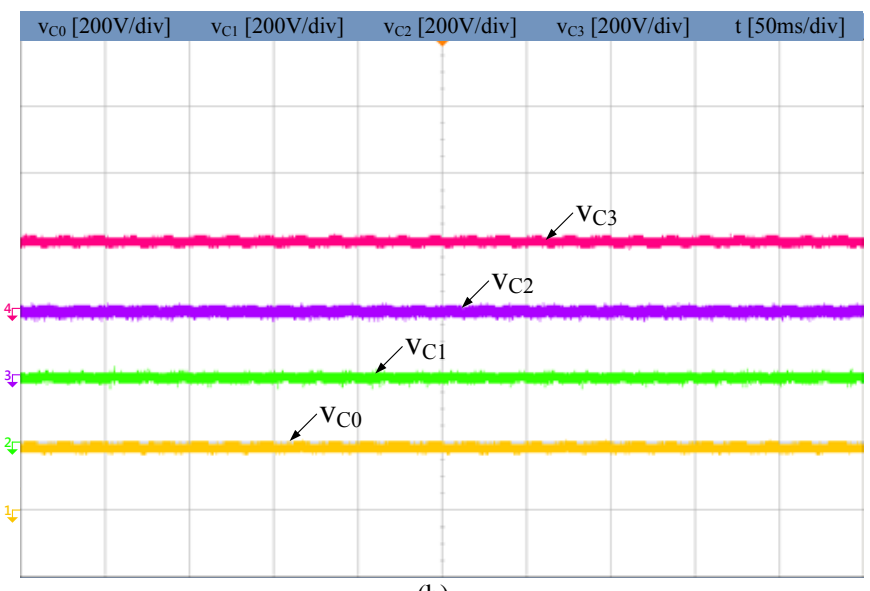

(b)

Fig. 9: Experimental results for three-level PD-PWM decoder: (a) switched output voltage $\mathrm{v}_{\mathrm{o}}$, arm currents $i_{\text {upper }}$ and $i_{\text {lower }}$, circulating current $i_{\mathrm{cm}}$, and output current $i_{\mathrm{o}}$, (b) individual module capacitor voltages $\mathrm{v}_{\mathrm{C} 0}, \mathrm{v}_{\mathrm{C} 1}, \mathrm{v}_{\mathrm{C} 2}, \mathrm{v}_{\mathrm{C} 3}$.

(which cancels in the line-to-line output voltage and hence reduces the overall inverter distortion). These results confirm that PWM of the overall MMC phase leg with a PD strategy and a per phase (instead of per arm) state machine post modulator decoder allows for the exploitation of the superior harmonic properties of the PD-PWM strategy.

\section{VIII.CONCLUSION}

This paper has discussed the design and implementation of per phase finite state machine PD-PWM post modulator decoders for modular multilevel converters. A methodology for developing optimised state machine decoders for MMCs that are capable of synthesising $2 \mathrm{~N}+1$ switched phase leg output voltage levels while still maintaining balance of the individual module capacitor voltages has been presented through its application to a two module per arm MMC. A simplified version of MMC PD-PWM post modulator decoder, able of synthesising $\mathrm{N}+1$ phase leg output switched voltage levels while also maintaining the individual module capacitor voltages balanced, has been introduced by its development to the same two module per arm MMC scenario. 


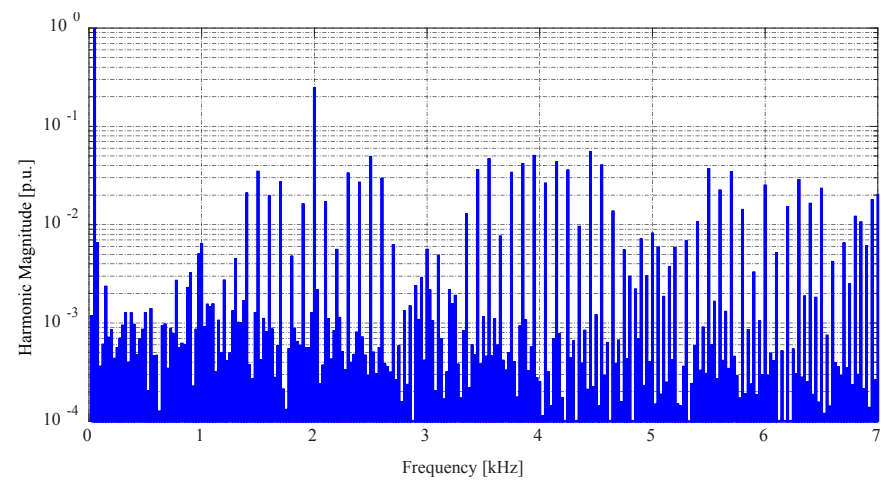

(a)

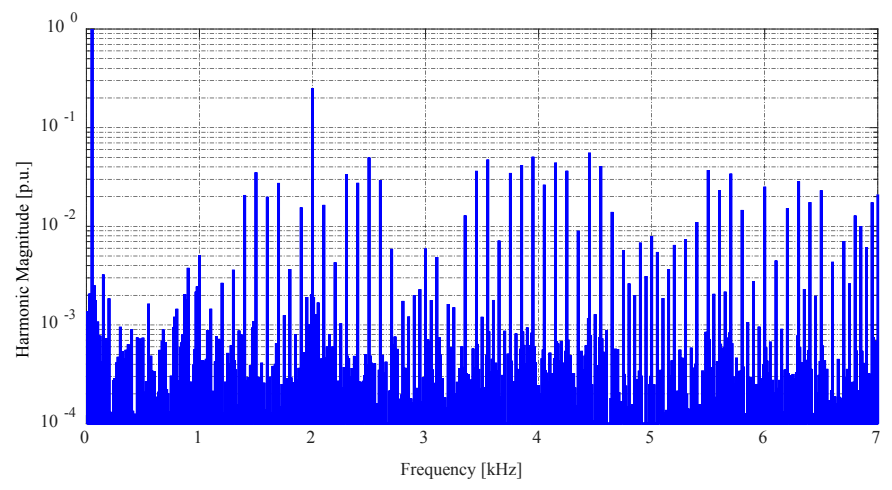

(b)

Fig. 10: Spectra of MMC phase leg switched output voltage $\mathrm{v}_{\mathrm{o}}$ for five-level PD-PWM ( $f_{\mathrm{c}}=2 \mathrm{kHz}, \mathrm{f}_{\mathrm{o}}=50 \mathrm{~Hz}, \mathrm{M}=0.9$ ): (a) simulation and (b) experiment.

Both of these methodologies have been extensively investigated using PSIM switched simulations and then experimentally confirmed using an exemplar MMC phase leg.

\section{ACKNOWLEDGEMENT}

The authors acknowledge support from the Australian Research Council (DP140102437), National Natural Science Foundation of China (51477030), and Joint Innovation Foundation of Jiangsu Province in China (BY2014127-15).

\section{REFERENCES}

[1] Lesnicar and R. Marquardt, "An innovative modular multilevel converter topology suitable for a wide power range", in Proc. IEEE Bologna Power Tech., vol. 3, Jun. 2003.

[2] M. A. Perez, S. Bernet, J. Rodriguez, S. Kouro and R. Lizana, "Circuit Topologies, modeling, control schemes, and applications of modular multilevel converters," IEEE Trans. Power Electron., vol. 30, no. 1, pp. 4-17, Jan. 2015

[3] H. Akagi, "Classification, terminology, and application of the modular multilevel cascade converter (MMC)", IEEE Trans. Power Electron., vol. 26, no. 11, pp. 3119 3130, Nov. 2011.

[4] S. Debnath, J. Qin, B. Bahrani, M. Saeedifard and P. Barbosa, "Operation, control, and applications of the modular multilevel converter : A review", IEEE Trans. Power Electron., vol. 30, no. 1, pp. 37 53, Jan. 2015.

[5] W. van de Merwe, P. Hokayem and L. Stepanova, "Analysis of the Ncell single phase MMC natural balancing mechanism", IEEE Jour. of Emerging and Selected Topics in Power Electron., vol. 2, no. 4, pp. 1149 1158, Dec. 2014.

[6] R. Darus, G. Konstantinou, J. Pou, S. Ceballos and V. Agelidis, "Comparison of phase-shifted and level-shifted pwm in the modular

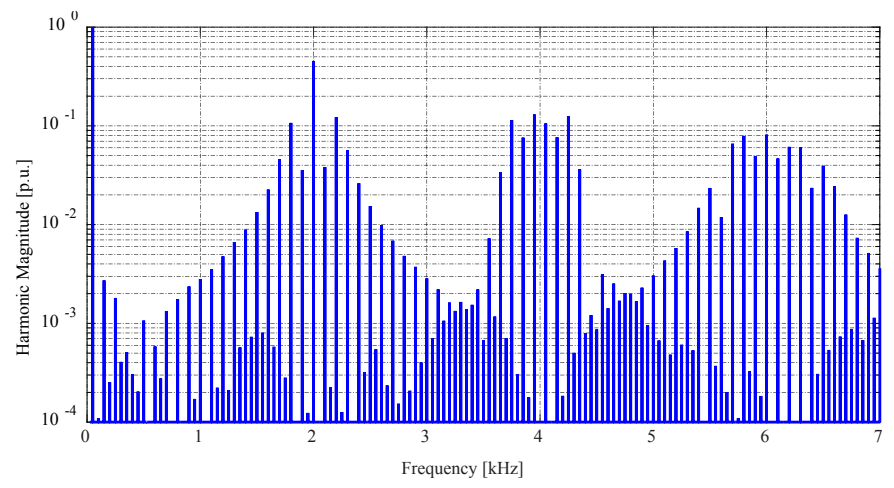

(a)

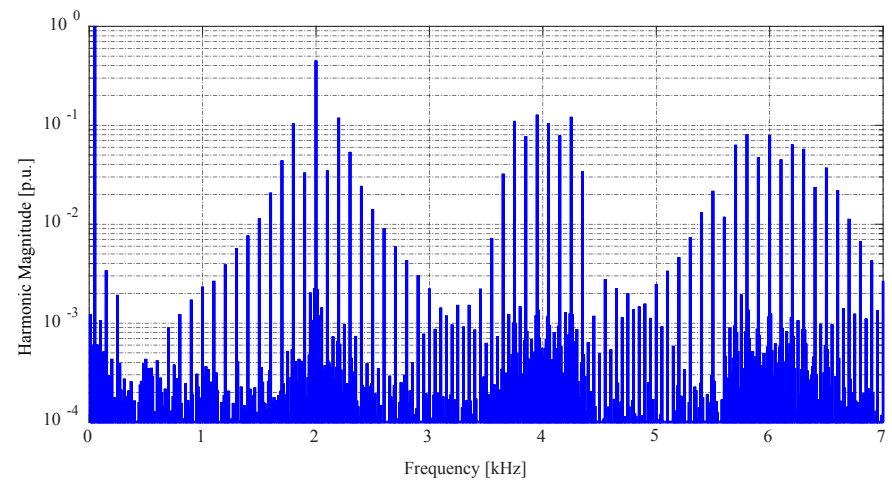

(b)

Fig. 11: Spectra of MMC phase leg switched output voltage $\mathrm{v}_{\mathrm{o}}$ for three-level PD-PWM $\left(\mathrm{f}_{\mathrm{c}}=2 \mathrm{kHz}, \mathrm{f}_{\mathrm{o}}=50 \mathrm{~Hz}, \mathrm{M}=0.9\right)$ : (a) simulation and (b) experiment.

multilevel converter", in Proc. IEEE Intl. Power Electron. Conf. (IPEC - ECCE Asia), pp. 3764 - 3770, 2014.

[7] T. Soong and P. W. Lehn, "Internal power flow of a modular multilevel converter with distributed energy resources," IEEE J. Emer. Sel. Topics Power Electron., vol. 2, no. 2, pp. 249-263, Jun. 2014.

[8] M. Hagiwara and H. Akagi, "Control and experiment of pulsewidth modulated modular multilevel converters," IEEE Trans. Power Electron., vol. 24, no. 7, pp. 1737-1746, Jul. 2009.

[9] L. Harnefors, A. Antonopoulos, S. Norrga, L. Angquist and H. Nee, "Dynamic analysis of modular multilevel converters," IEEE Trans. Ind. Electron., vol. 60, no. 7, pp. 2526-2537, Jul. 2013.

[10] G. P. Adam, O. Anaya-Lara, G.M. Burt, D. Telford, B. W. Williams, J. R. McDonald, "Modular multilevel inverter: Pulse width modulation and capacitor balancing technique," in Power Electronics, IET , vol.3, no.5, pp.702-715, September 2010.

[11] Y. Zhang, G. P. Adam, T. C. Lim, S. J. Finney and B. W. Williams, "Analysis of modular multilevel converter capacitor voltage balancing based on phase voltage redundant states," IET Power Electron., vol. 5, no. 6, pp. 726-738, 2012.

[12] D. G. Holmes and T. Lipo, Pulse Width Modulation for Power Converters: Principles and Practice, Hoboken, NJ, USA: Wiley, 2003.

[13] Teixeira, B. P. McGrath and D. G. Holmes, "A state machine decoder for phase disposition pulse width modulation of three-phase coupled inductor semi-bridge converters", in Proc. IEEE Energy Conversion Congress and Exposition (ECCE), pp. 3731 3738, 2014.

[14] P. McGrath, C. A. Teixeira, D. G. Holmes, "Optimised phase disposition (PD) modulation of a modular multilevel converter using a state machine decoder," in Energy Conversion Congress and Exposition (ECCE), 2015 IEEE , vol., no., pp.6368-6375, 20-24 Sept. 2015.

[15] B. P. McGrath, T. Meynard, G. Gateau and D. G. Holmes, "Optimal modulation of flying capacitor and stacked multicell converters using a state machine decoder", IEEE Trans. Power. Electron., vol. 22, no. 2, pp. 508 516, Mar. 2007. 